Anuario Latinoamericano Ciencias Políticas

y Relaciones Internacionales

vol. 6, 2018

pp. 283-287

DOI: $10.17951 / \mathrm{al} .2018 .6 .283-287$

\section{Dembicz Katarzyna (2016), PosCuba. Lo imponderable de la transformación insular, Hipermedia Ediciones-Deinøs-Ensayo, Madrid}

\author{
Dembicz Katarzyna (2016), Post-Cuba. \\ The Imponderables of Insular Transformation, \\ Hipermedia Ediciones-Deinøs-Ensayo, Madrid.
}

Si observamos mediante una línea de tiempo los procesos de transición en los países exsocialistas de tipo soviético hacia una economía de mercado capitalista, en las últimas décadas del siglo XX y primeros lustros de la siguiente centuria, podemos mencionar que Polonia y Cuba se encuentran en los extremos opuestos de dicha recta. Polonia resulta un caso destacado porque fue un pionero exitoso en la eliminación de los vestigios socialistas, tal como se lo propuso uno de los arquitectos de su transición: Leszek Balcerowicz. ${ }^{1}$ En los años cincuenta y sesenta del siglo XX se había intentado reformar el sistema socialista en Europa Central, pero sin éxito (Chavance 1992: 45-54). La situación cambió radicalmente a partir de las protestas obreras en el verano de 1980, lo que produjo diversos acontecimientos: el reconocimiento del sindicato independiente Solidaridad, el inicio de una transformación institucional irreversible hacia una economía de mercado capitalista y un impulso democratizador. Estrategias inspiradas en el diseño institucional de Europa Occidental. En los ochenta, Polonia fue observada con un particular interés en Europa Central y el resto de los países socialistas, entre ellos Cuba. Por su parte, el sistema socialista cubano, de inspiración soviética, quedó desamparado tras la caída del Muro de Berlín en noviembre de 1989, lo que complicó su viabilidad; se esperaba el colapso del sistema en cualquier momento, pero aún no ha llegado. Cuba mostró una capacidad adaptativa notable en un ambiente adverso marcado por los años dorados de la neoliberalización a nivel global. El siglo XX quedó atrás y no fue hasta el año 2007 - una vez que se dio el relevo del poder entre los hermanos Fidel y Raúl Castro- cuando se habló de reformas estructurales del sistema socialista cubano (Mesa-Lago 2015: 23), concepto que despertó dudas; después se usó el término transición, igualmente confuso,

1 Balcerowicz estaba consciente de la inherente resistencia al cambio de los sistemas socialistas de tipo soviético, por lo tanto, propuso hacer una reforma radical que dejara poca opción a un eventual retorno al estado inicial (Balcerowicz 1995: 51). 
¿transición hacia dónde o hacia qué? O, tal como lo plantea Renaud Lamber (2017: 6) en un abordaje reciente del tema: ¿hacia mercado sin capitalismo?

Katarzyna Dembicz en su PosCuba nos ofrece algunas respuestas al último cuestionamiento. Pero antes de abordar este punto, queremos subrayar la posición privilegiada de la autora al vivir inmersa en un contexto histórico que le permitió experimentar y analizar los dos extremos de la transición de los sistemas socialistas en cuestión, con toda la complejidad que ello implica. Originaria de Varsovia tuvo la dicha de nacer casi latinoamericana fuera de América Latina; su padre, Andrzej Dembicz, fue un destacado estudioso de ese continente a nivel global, al cual le heredó un amplio conocimiento que se refleja en su formación universitaria. Además, trabajó por casi 25 años en el Centro de Estudios Latinoamericanos de la Universidad de Varsovia, hoy extinto; ha publicado una cantidad importante de libros, capítulos de libros y artículos científicos sobre América Latina, donde Cuba ocupa un lugar especial en su producción. De igual forma destaca su dirección y coordinación del proyecto científico denominado: “Quo vadis Cuba?", lo que ha desembocado en otros estudios sobre la Isla, como el artículo publicado en 2016 junto con E. Biczyńska: La noción de Cuba entre los emigrados cubanos y sus diferencias geográficas, “Quivera”, No.18, o la edición del libro Cuba: ¿quo vadis? (2013).

PosCuba es un libro interesante que puede ser entendido desde distintos enfoques metodológicos: la sociología, los estudios políticos o la transitología, por mencionar algunos. Sin embargo, conforme se avanza en su lectura, se descubren muchos elementos de la perspectiva de historia global contemporánea, especialmente en un espacio que a primera vista pudiera resultar diminuto en este contexto, pero que dada su trayectoria histórica en el siglo XX, Cuba resultó ser uno de los grandes actores globales, cuyo peso para moldear una ruta histórica de estas dimensiones es comparable con lo hecho por otros países de América Latina, Europa e incluso con los mismos Estados Unidos o la Unión Soviética. Situación que reivindica el papel de América Latina en estos escenarios globales, no obstante la persistencia de importantes metanarrativas en la historia global, que pretenden periferizar a este continente en su discurso. De los elementos de historia global contemporánea destacan al menos cuatro: la vinculación con diversos fenómenos, la conexión con otras historias, el reconocimiento de rupturas o continuidades y, finalmente, el enfoque transnacional y transdisciplinario. Veamos cómo se refleja cada uno de ellos en la exposición de Katarzyna Dembicz.

En primer lugar, destacamos la existencia de vinculaciones entre diversos fenómenos que encuentran explicaciones comunes para una serie de problemas manifestados en distintas áreas de estudio. Las dificultades que ha experimentado Cuba fueron inherentes al funcionamiento de los sistemas socialistas de tipo soviético aún antes de su desaparición, los cuales se caracterizaron por la centralización de sus actividades por parte del Estado y la influencia que el partido hegemónico mantuvo en éstas. Lo anterior se reflejó de diversas formas: gestión económica ineficiente, déficits de legitimidad interna y externa 
por parte de los respectivos gobiernos y falta de libertades civiles, que en algunos casos llegaron incluso a considerarse violaciones a los derechos humanos. El socialismo en Europa Central se impuso en la mesa de negociación política al término de la Segunda Guerra Mundial, mientras que en Cuba se derivó de una lucha armada que derrocó a un régimen dictatorial. Las transformaciones socioeconómicas que se vivieron durante los años setenta y ochenta del siglo $\mathrm{XX}$, que incluían una transformación notable de la base técnica-tecnológica, hizo que estos sistemas perdieran viabilidad en el contexto internacional, especialmente por su postura aislacionista que devino más difícil de sostener por parte de este tipo de regímenes, que enfrentaron un contexto integracionista no forzado a nivel global. Esta situación generó una presión sociopolítica que minó las bases institucionales de los sistemas socialistas de tipo soviético, sobre todo en Europa Central, por su incapacidad de transformación sin perder sus elementos básicos.

Como segundo punto, subrayamos las conexiones que se manifiestan en una variedad de otras historias que le dan sentido a un periodo de tiempo dado. Por ejemplo, existe un grupo de autores (Bobes 2015) que coinciden en señalar la inexistencia de voluntad política por parte del gobierno cubano para implementar las reformas económicas del régimen socialista, perspectiva que Katarzyna Dembicz no comparte porque, según argumenta, si no existiera esa disposición política no podría avanzarse en la materia. Pero, como bien lo apunta nuestra autora, no sólo se trata de reformas económicas, son también importantes otros cambios en el ámbito sociocultural de la Isla. Incluso, estas otras historias van hasta el mismo entorno familiar como un núcleo sustancial de la sociedad, al poner en relieve su influencia, que a veces se pasa por alto para privilegiar una visión macro de los procesos de transformación institucional. Entonces, la articulación entre lo micro (núcleo familiar) y lo macro (contexto geopolítico internacional) le dan sentido a otras historias, tal como se observa en los procesos de éxodo hacia otras sociedades en busca de alternativas por parte de los cubanos isleños; o en su defecto, dentro de esta misma línea, se inscribe la visión que nos comparte la autora sobre los miembros más jóvenes de las familias, para quienes la figura de Fidel Castro puede reducirse al Gran Abuelo, cuya indumentaria deportiva se contrasta con el uso de su tradicional uniforme verde olivo, cargado de simbolismo para las primeras generaciones de la Revolución.

Como tercer punto, sobresale el reconocimiento de rupturas y continuidades en el estudio del devenir histórico, lo que permite establecer una periodización relativamente coherente. En este sentido, K. Dembicz señala tres procesos de transformación con el objetivo de recordarnos que la reforma más reciente no es algo nuevo para la sociedad cubana. El primero de estos procesos se inscribió en el contexto de la Primera Guerra Mundial, la Isla retomó sus actividades productivas dirigidas hacia la exportación de azúcar a mercados mundiales, lo que se manifestó en una reestructuración clasista y en movimientos estudiantiles, sindicales, así como de personas de color. El segun-

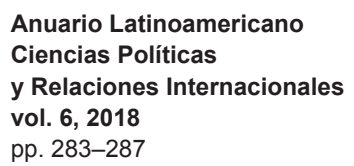

pp. 283-287

DOI: $10.17951 / \mathrm{al} .2018 .6 .283-287$ 
do proceso inició con la Revolución en 1959 y duró hasta 1988. Durante ese tiempo funcionó un sistema socialista de inspiración soviética. Mientras que el tercer periodo se caracteriza por una evidente debacle del sistema anterior ante los cambios manifestados en el ámbito global, lo cual abrió paso a otro fenómeno de transformación mediante las primeras reformas económicas. Pero es importante recordar, una vez más basados en la experiencia de Polonia, que aun en un periodo de transformación institucional existen crisis políticas o socioculturales cuando los resultados originalmente planteados no son los que se esperaban; la malaise tiende a ser minimizada o silenciada oficialmente, aunque al final de cuentas circunstancias imprevisibles brotaran a la superficie, lo que tarde o temprano levantará cuestionamientos sobre el proceso de cambio en su conjunto o, en su defecto, generará una ruptura dentro de cierta continuidad basada en un consenso previo.

Por último, encontramos en esta obra una perspectiva que privilegia un análisis transnacional y transdisciplinario; es decir, se ponen en relieve elementos locales que rebasan el contenedor tradicional de espacio como lo es el Estado-nación y se añade un enfoque que supera la división del conocimiento en áreas de estudio. Un factor analítico inherente en el cambio institucional es la interacción entre diversos espacios que desborda las fronteras de lo nacional donde influyen variables extraterritoriales. En el caso de Polonia destaca, por un lado, el papel que el país jugó en la órbita de influencia soviética mientras que, por otro, existió un claro interés en la trayectoria histórica polaca por parte de Karol Wojtyła, cuya influencia fue esencial en su envestidura papal de Juan Pablo II. En Cuba se percibe un fenómeno similar. Por una parte, fue un actor destacado durante la Guerra Fría apoyado por su principal aliado de aquel entonces: la Unión Soviética, mientras que, por la otra, el espectro geopolítico internacional cambió a partir de noviembre de 1989, lo que llevó a la Isla por un camino que desembocó en un proceso de reforma, que pretende cambiarle el rostro, no obstante que aún se discute el hacia dónde se dirigirá este cambio institucional. Tanto en Polonia como en Cuba la transformación de sus regímenes ha abarcado amplios sectores de la sociedad, lo que demanda realizar un análisis transdisciplinario con la finalidad de tener una mejor compresión de estos fenómenos desde un punto de vista global.

Para concluir nuestros comentarios sobre PosCuba, quisiéramos señalar que es una importante contribución para la historia global contemporánea, aun sin proponérselo de manera explícita. No sólo aumenta nuestro conocimiento sobre los procesos de cambio institucional en su conjunto, sino también interconecta estos fenómenos tanto en Europa Central como en América Latina mediante los casos de Polonia y Cuba, respectivamente. Además, matiza el carácter evolutivo de la transición, porque, aunque es un proceso de cambios graduales, éstos no garantizan la continuidad del mismo, sino más bien es factible que presenten algunas regresiones como sucede actualmente con los impulsos democráticos en Polonia, aun cuando el país fue aceptado en la Unión Europea desde el 1 de mayo de 2004, con lo que terminaría en 
teoría su transición. Lo anterior también es una situación que debe tomarse en cuenta para el caso cubano, debido a que la regresión en el proceso de transición hacia una economía de mercado y una creciente democratización en la sociedad no sólo puede generarse de manera endógena; existe un contexto internacional que influye decisivamente en el proceso, como es el caso del relevo presidencial en los Estados Unidos, lo que obliga a la Isla a recorrer de nuevo un camino que parecía andado. En concreto, la transición también manifiesta, en algunos casos, su carácter reversible. Otros valiosos aportes de Katarzyna Dembicz, derivados de la experiencia polaca y que será útil considerarlos para el proceso de transición en Cuba, es que la clase política de la Isla está lejos de ser ingenua, como en algún momento se consideró para Polonia según la autora (p.41). Además, en el país latinoamericano, obviamente no ha existido una fuerte influencia de actores externos, como Jeffrey Sachs para los casos de Europa Central en general. También existe cierta cautela con respecto a la confianza de la iniciativa privada. Elementos que en conjunto pueden particularizar el caso cubano gracias a la experiencia adquirida en otras sociedades.

\section{Referencias bibliográficas}

Balcerowicz L. (1995), Socialism, Capitalism, Transformation, Central European University Press, Budapest.

Chavance B. (1992), Les réformes économiques à l'Est de 1950 aux années 1990, Nathan, Paris.

Mesa-Lago C. (2015), Las reformas estructurales de Raúl Castro: análisis y evaluación de sus efectos macro y micro, en: ¿Ajuste o transición? Impacto de la reforma en el contexto del restablecimiento de las relaciones con Estados Unidos, V. C. Bobes (ed.), FLACSO, México, pp. 21-45.

Lambert R. (2017), Cuba veut le marché... sans le capitalisme, "Le Monde Diplomatique", vol. 64, no 763, octubre, pp. 6-7.

Bobes V.C. (ed.), (2015), ¿Ajuste o transición? Impacto de la reforma en el contexto del restablecimiento de las relaciones con Estados Unidos, FLACSO, México.

\section{Carlos Riojas}

Departamento de Estudios Regionales

CUCEA, Universidad de Guadalajara, México

criojas@cucea.udg.mx

https://orcid.org/0000-0003-3657-6004



pp. 283-287

DOI: 10.17951/al.2018.6.283-287 